\title{
THE LIFE-CYCLE OF THE SPIDER PHIDIPPUS COCCINEUS (SALTICIDAE) UNDER LABORATORY CONDITIONS*
}

\author{
By Beatrice T. Gardner \\ Department of Psychology, University of Nevada
}

The jumping spider, $P$. coccineus, spends the winter in penultimate instar within a heavy hibernating web under stones. Usually, the spider undergoes its final molt just before it emerges, in April or in May, and resumes its nomadic bushtop existence. Mature males appear before the females do. In the spring of 1967 , for example, twenty spiders were collected during the first week of April: seven of these were mature males, three were mature females, and the remaining ten were females in the penultimate instar that became mature between 12 April and 23 April. The earlier date of reaching maturity for males yields a chi-square of $7.9, \mathrm{df}=\mathrm{I}, \mathrm{p}<.005$. Courtship and mating occur in late spring and early summer, but after mid-July adult specimens of $P$. coccineus are very difficult to find, although spiderlings of that species are abundant.

For several years, we have observed that spiders overwintering in the laboratory, with continued warmth and abundance of prey, molted abnormally early and showed a striking concordance on this anomalous date of reaching maturity. Furthermore, even though the final molt is some three months premature, the males still became mature between one and two weeks ahead of the females. The spiders that matured early also died early and, in 1967, over half were dead before spiders that had spent the winter in the field began to emerge. Table I presents these data for 52 spiders which spent the winter in the laboratory. These spiders came from the same population as the 20 that became mature by 23 April.

A similar phenomenon has been observed in the reproductive behavior of Phidippus apacheanus. Under field conditions, these spiders mate in October-November, and the gravid female spends the winter in a heavy web under stones. Although the dates for egg-laying and hatching under field conditions are not known, it seems likely that these events do not occur until spring. At any rate, spiderlings of this species first appear in June, only a few weeks before those of $P$. coccineus. Four gravid females taken to the laboratory laid their

*This research was supported by Public Health Service Research Grant MH-08938 from the National Institute of Mental Health.

*Manuscript received by the editor May 22, 1967 
eggs between I2 December and 30 December; these eggs hatched in January and mobile spiderlings emerged from the nest in February. Parenthetically, two of the early maturing $P$. coccineus females were mated with early maturing males; the eggs were laid in February, and the spiderlings emerged in March.

The fact that both sexual maturity and death in $P$. coccineus were accelerated by overwintering in the laboratory implies that, like the proverbial candle that cannot burn at both ends, the life span of this spider depends more on metabolic processes than on calendar time.

By accelerating maturity with laboratory maintenance conditions, it is possible to bring together young adults of $P$. coccineus and $P$. apacheanus. Thus, the technique could provide the basis for a study on mechanisms of reproductive isolation in these two species. Normally, the adults of apacheanus and coccineus appear in the same habitat at different times of the year, so that the time at which each species is courting does not overlap (Gardner, I965).

Finally, the fact that the spiders had been under constant conditions of warmth and abundance of prey for about three months without molting, while during July-September the intermolt interval for $25 P$. coccineus was $27 \pm 5.5$ days, and that they subsequently molted within a relatively short time (for males, 3 January $\pm \mathrm{I} 3$ days, and for females I 3 January \pm I I days), suggests the following

\section{TABLE I}

Maturity and Survival of $P$. coccineus Overwintering in the Laboratory

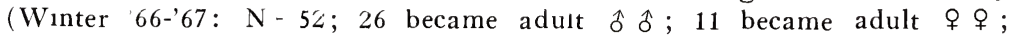
15 died before maturity.)

Before the

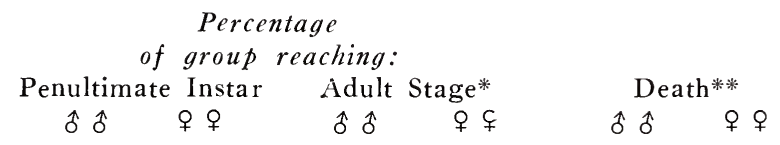

1st day of:

\begin{tabular}{|c|c|c|c|c|c|c|}
\hline Oct. & 0 & $11 \%$ & & & & \\
\hline Nov. & $96 \%$ & $89 \%$ & & & & \\
\hline Dec. & $4 \%$ & & 0 & & & \\
\hline Jan. & & & $36 \%$ & 0 & 0 & 0 \\
\hline Feb. & & & $64 \%$ & $100 \%$ & $28 \%$ & $11 \%$ \\
\hline March & & & & & $32 \%$ & $22 \%$ \\
\hline April & & & & & $8 \%$ & $22 \%$ \\
\hline
\end{tabular}

*The $\hat{\delta} \hat{\delta}-q+$ difference is significant at $\mathrm{p}=04$, Fisher's exact method.

**32\% of the males and $44 \%$ of the females survived beyond April 1 and were released in the field. 
mechanism for controlling the final molt. Suppose that constant conditions of warmth and abundance of food produce a regular interval of four weeks between molts throughout the summer but that a hormone is activated following the penultimate instar which inhibits further molting. Gradually, this inhibitory substance wears off. Then the spider can respond to environmental conditions again and if, during a brief sampling period, it is exposed to favorable environmental conditions, it will molt. Such a mechanism could be highly adaptive as the spiders would not initiate a disastrous breeding season during an Indian Summer, and could take advantage of an early spring.

Some fragmentary evidence supports this hypothesis: occasionally, spiders have been collected in their heavy webs during the winter, and brought to the laboratory where they soon resumed feeding. Under these conditions, two penultimate males collected on 4 December became mature on 5 January and 12 January respectively. Further experiments along these lines, that is, with favorable environmental conditions administered in short samples at different times during the winter would test the suggestions on inhibition. Furthermore, the favorable conditions should be specified more closely, as Turnbull (1962, 1965) has done for the relationship between daily food consumption and development in Linyphia triangularis and Agelenopsis potteri.

Gardner, B. T.

\section{REFERENCES}

1965. Observations on three species of Phidippus jumping spiders (Araneae: Salticidae). Psyche, 72: 133-147.

Turnbull, A. L.

1962. Quantitative studies of the food of Linyphia triangularis Clerck (Araneae: Linyphiidae). Can. Ent., 94: 1233-1249.

1965. Effects of Prey Abundance on the Development of the Spider Agelenopsis potteri (Blackwall) (Araneae: Agelenidae). Can. Ent., 97: 141-147. 


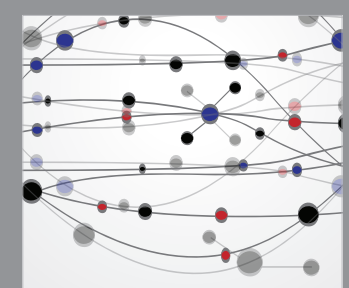

The Scientific World Journal
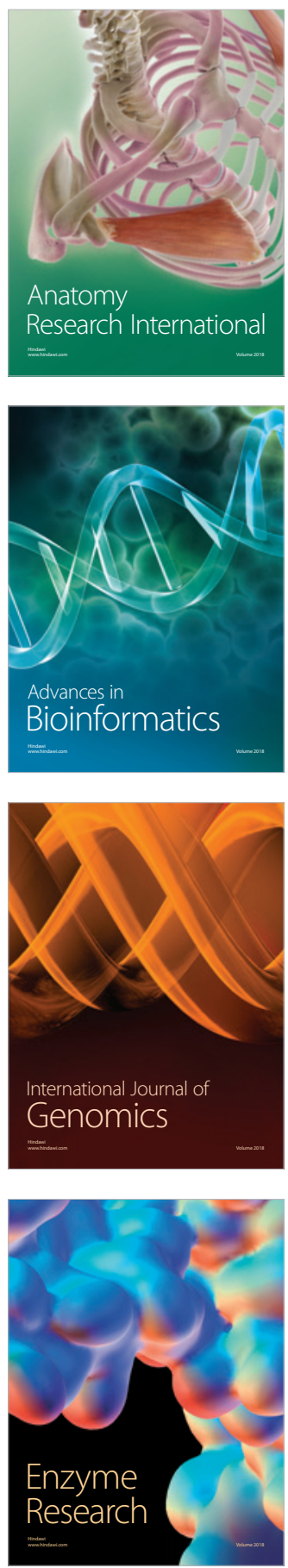
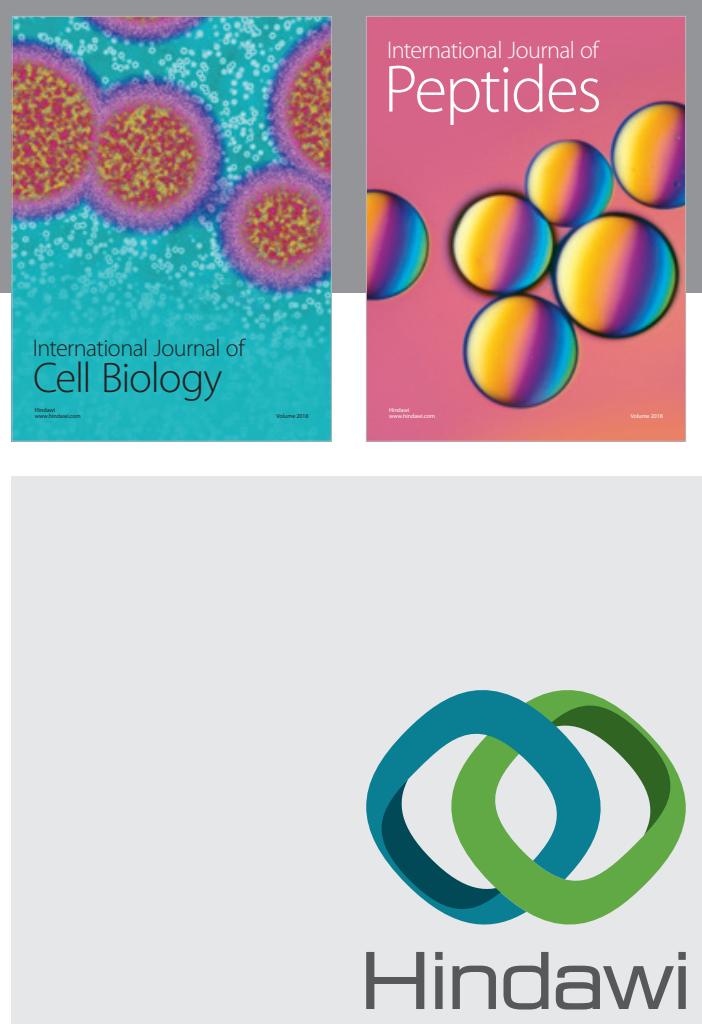

Submit your manuscripts at

www.hindawi.com
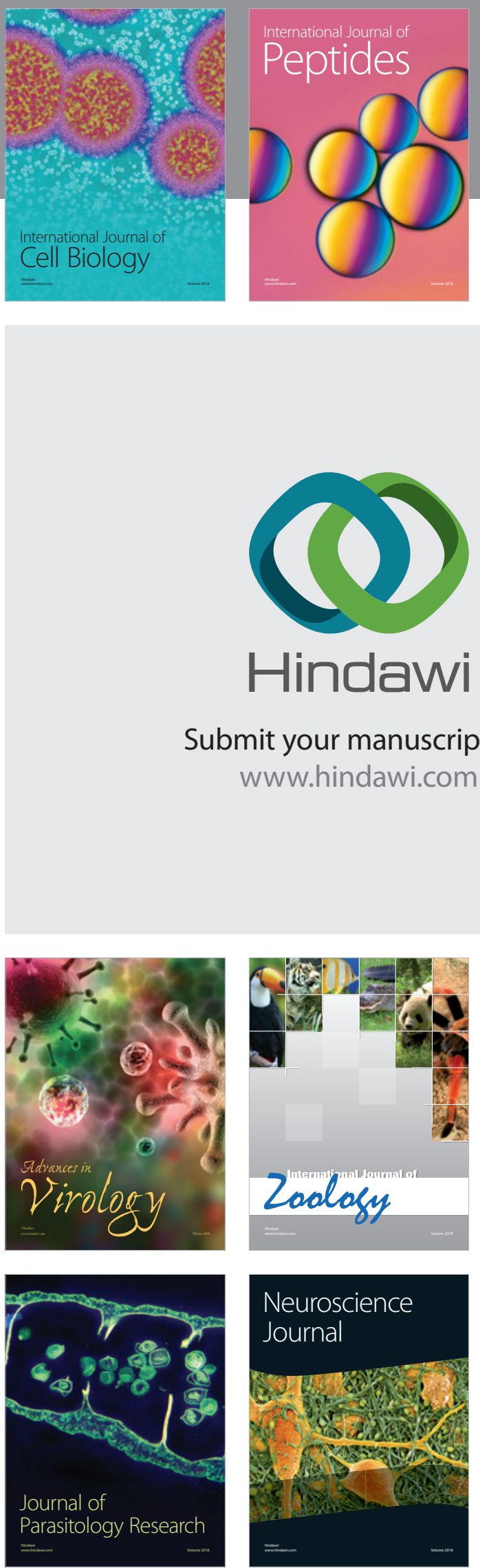
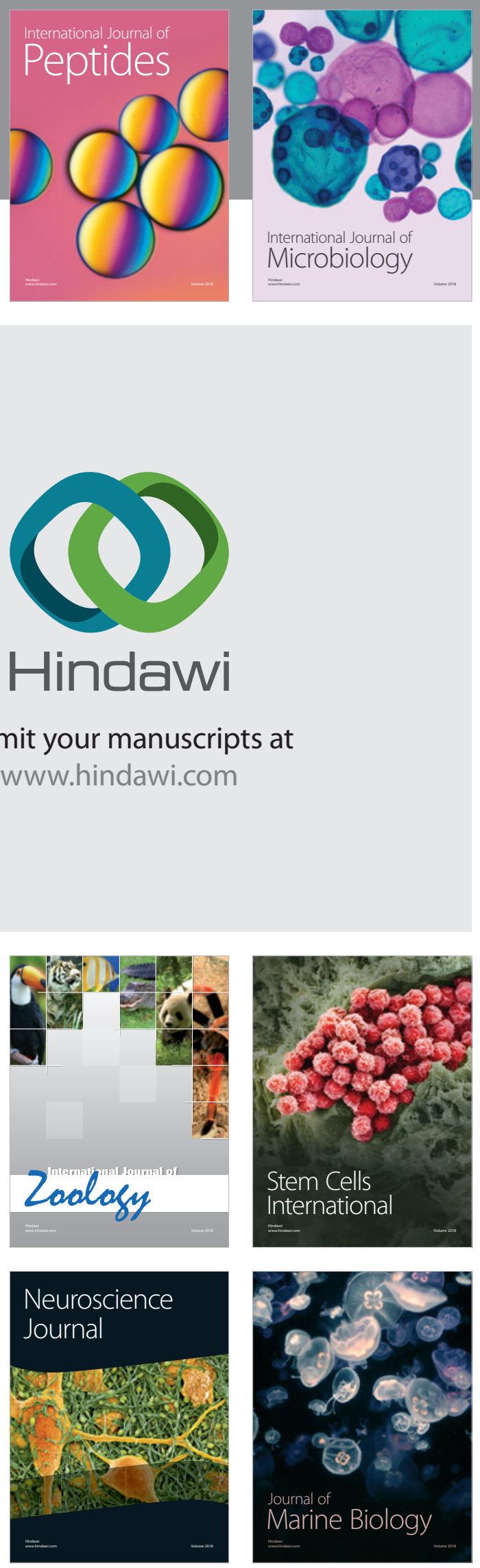
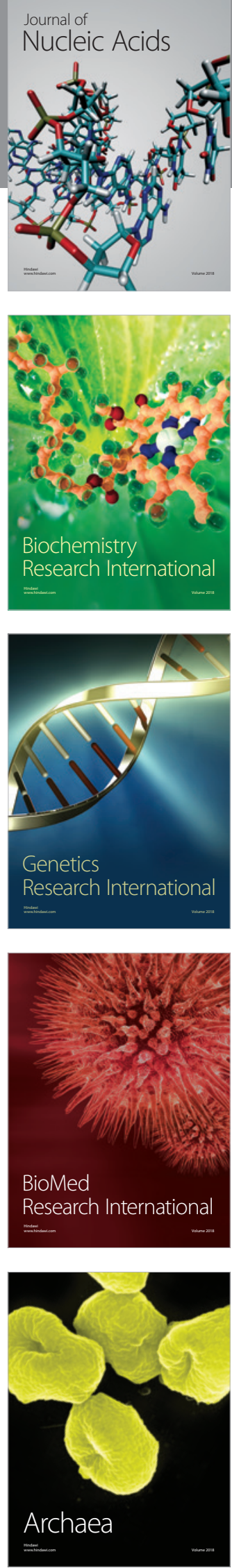